\title{
Entrapment of an Accessory Superficial Peroneal Sensory Nerve
}

\author{
Michael Rubin, David Menche and Mark Pitman
}

\begin{abstract}
A 29 year old man had an accessory branch of the superficial peroneal nerve which entered the foot by rostro-caudally traversing the lateral malleolus laterally. The nerve was entrapped by a fascial band, resulting in pain over the lateral malleolus and dorsum of foot. Symptoms resolved when the nerve was surgically released.

RÉSUMÉ: Séquestration d'un nerf sensitif poplité externe accessoire. Un homme de 29 ans avait une branche sensitive accessoire du nerf poplité externe qui atteignait le pied en traversant la malléole latéralement. Le nerf était séquestré par une bande aponévrotique, causant de la douleur au niveau de la malléole et du dos du pied. Les symptômes sont disparus lorsque le nerf a été dégagé chirurgicalement.
\end{abstract}

Can. J. Neurol. Sci. 1991; 18: 342-343

After supplying the peroneus longus and brevis muscles, the superficial peroneal nerve (SPN) divides into medial and lateral terminal branches which run anteriorly over the ankle to supply most of the dorsal foot with sensory innervation. 1 Anatomic variation of the SPN supplying an accessory motor branch which runs behind the lateral malleolus to the extensor digitorum brevis occurs in $19-28 \%$ of persons. ${ }^{2,3.4}$ Accessory sensory branches, however, have not been described to our knowledge. Furthermore anatomic variations and disorders of nerves supplying the foot have received much less attention than those to the hand. We report such an anatomic variant involved in an entrapment syndrome and cured by surgical release of the nerve.

\section{Case Report}

A 29 year old man presented with a 3 month history of pain over the right lateral malleolus and proximal dorsum of the foot without weakness or numbness. There was no personal history of trauma or fracture and no family history of neurologic disorder. Examination revealed a firm, cord-like structure traversing the lateral aspect of the right lateral malleolus in a rostro-caudal direction. Manipulation of the cord exacerbated the discomfort but caused no paresthesias. There was no Tinel's sign. There were no other palpably enlarged nerves. The remainder of the examination was unremarkable.

Nerve conduction studies were performed in standard fashion ${ }^{5}$ using a Dantec Counterpoint Electromyograph (Dantec Electronics Inc, Allendale, NJ). Conduction along the right common peroneal motor nerve, superficial peroneal sensory nerve (Figure la) and sural nerve was normal. There was no accessory peroneal motor nerve as evidenced by the lack of a response recorded over the extensor digitorum brevis on stimulating behind the lateral malleolus. Stimulation of the cord-like structure resulted in no contraction or recordable response over the extensor digitorum brevis, abductor digiti minimi or abductor hallucis brevis muscles. Antidromic stimulation of the superficial peroneal sensory nerve, approximately $12 \mathrm{~cm}$ proximal to the ankle at the anterior edge of the fibula ${ }^{6.7}$ elicited a small $(2.8 \mu \mathrm{V})$, slowly conducting (33.3 $\mathrm{m} / \mathrm{s}$ ) sensory potential over the cord-like structure at the lateral malleolus (Figure 1b). This response was easily reproduced on multiple attempts. Slight movement of the recording electrode to either side of the structure resulted in loss of the recorded potential. Stimulation of the sural nerve in the posterior mid-calf region resulted in no recorded response over this structure. EMG of intrinsic foot muscles including the extensor digitorum brevis was normal. $X$-ray study of the foot and ankle was negative. At surgery, a constricting fascial band was found overlying the nerve as it crossed the lateral malleolus. This band was incised with prompt resolution of symptoms and no residual numbness.

\section{Discussion}

The SPN usually terminates as the medial dorsal cutaneous and intermediate dorsal cutaneous nerves. Our patient had a palpable intermediate dorsal cutaneous nerve with a normal sensory response, recorded in the usual fashion (Figure 1a).6.7 In addition, another nerve was palpable over the lateral malleolus, well lateral to the intermediate dorsal cutaneous nerve. Stimulation of this nerve resulted in no motor response. However, a sensory response was elicited antidromically over this nerve (Figure 1b) by stimulation at the anterior edge of the fibula, at the site of stimulation where one stimulates for superficial peroneal recordings. 6,7 This suggests that the accessory nerve was indeed a sensory branch of the SPN. Furthermore, moving the recording or stimulating electrode even slightly resulted in loss of the

From the Department of Neurology and Neuroscience, Laboratory of Clinical Neurophysiology (EMG), The New York Hospital-Cornell Medical Center (M.R.) and the Department of Sports Medicine, Hospital for Joint Diseases, Orthopedic Institute, New York (D.M., M.P.)

Presented in part at the 37th AAEM Annual Scientific Meeting, Chicago, Illinois, September 7-8, 1990

Received October 10, 1990. Accepted December 20, 1990

Reprint requests to: Dr. Michael Rubin, Department of Neurology, The New York Hospital-Cornell Medical Center, 525 East 68th Street, Rm K-615, New York, NY, U.S.A. 10021 


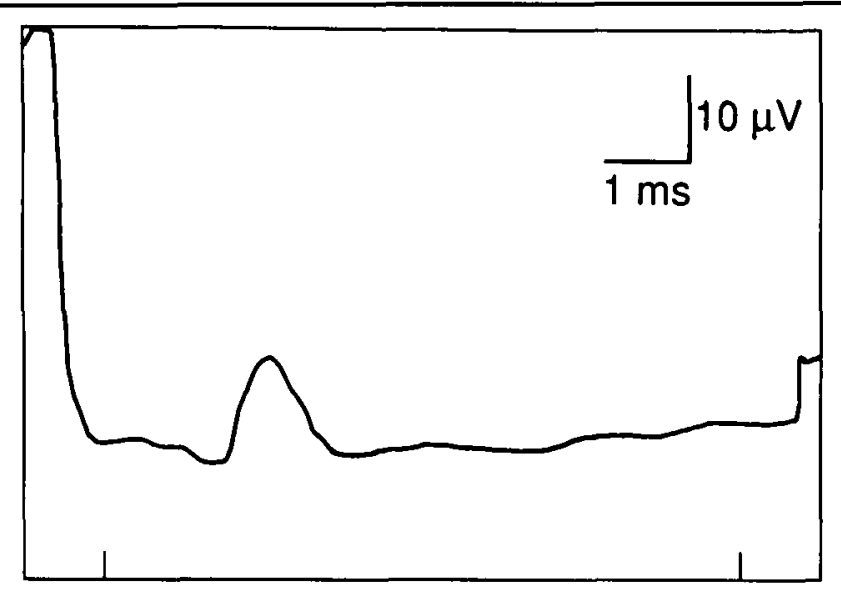

Figure $1 \mathrm{~A}$

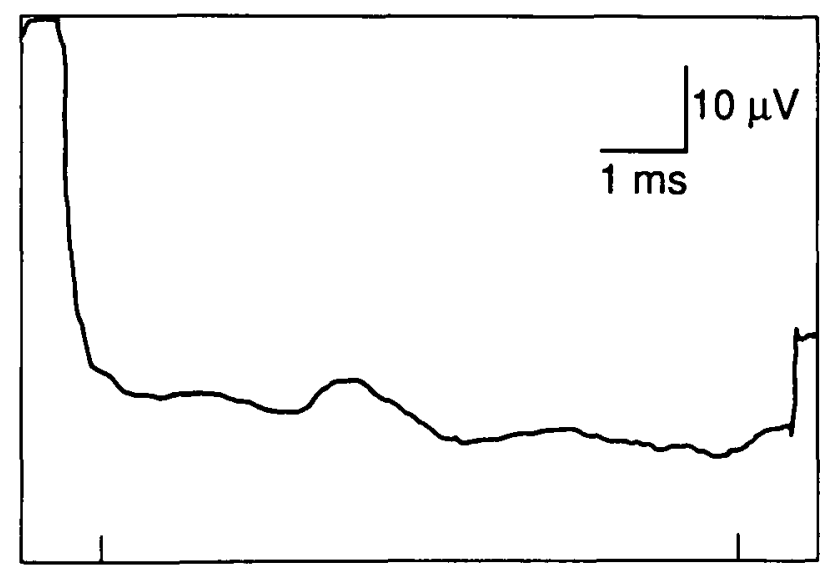

Figure 1B

Figure I(A): - Normal right superficial peroneal sensory nerve response using standard recording and stimulating technique. 6.7 $(B)$ - - Accessory superficial peroneal sensory nerve response with recording electrode laterally over lateral malleolus and stimulating as in $I A$. response, indicating that the response originated in the underlying structure, and was not volume-conducted from distal nerves. Thus, we conclude that this nerve, seen at surgery, was a sensory branch of the SPN.

Nearly 40 variations in the terminal sensory branching pattern of the SPN have been described. ${ }^{8}$ These however were primarily in the anastomotic pattern of its branches, and none demonstrated a SPN branch crossing laterally over the lateral malleolus. All described branches were located well medial to the malleolus. This unusual location lateral to the lateral malleolus, being completely exposed and unprotected, may have predisposed the nerve to recurrent minor trauma with resultant fibrosis and entrapment.

\section{ACKNOWLEDGEMENTS}

We gratefully acknowledge the assistance rendered by Drs. Robert Meislin, Richard Gasalberti and David Zelouf in the care of this patient.

\section{REFERENCES}

1. Stewart JD. Focal Peripheral Neuropathies. New York: Elsevier, 1987: 290-291.

2. Gutmann L. Atypical deep peroneal neuropathy in presence of accessory deep peroneal nerve. J Neurol Neurosurg Psychiatry $1970 ; 33 ; 453-456$.

3. Infante E, Kennedy WR. Anomalous branch of the peroneal nerve detected by electromyography. Arch Neurol 1970; 22: 162-165.

4. Lambert EH. The accessory deep peroneal nerve. A common variation in innervation of extensor digitorum brevis. Neurology 1969; 19: 1169-1176.

5. Kimura J. Electrodiagnosis in Diseases of Nerve and Muscle: Principles and Practice. Philadelphia: FA Davis: 1983: 105-14I.

6. Izzo KL, Sridhara CR, Lemont $\mathrm{H}$, et al. Sensory conduction studies of branches of the superficial peroneal nerve. Arch Phys Med Rehabil 1981; 62: 24-27.

7. Jabre JF. The superficial peroneal sensory nerve revisited. Arch Neurol 1981; 38: 666-667.

8. Kosinski $\mathrm{C}$. The course, mutual relations and distribution of the cutaneous nerves of the metazonal region of leg and foot. J Anat 1926; 60: 274-297. 